\title{
The interlocking paths of development to emphasizer adjective pure ${ }^{*}$
}

\author{
Sigi Vandewinkel and Kristin Davidse \\ University of Leuven, Belgium
}

\begin{abstract}
This study deals with the emphasizing use of adjective pure, as in pure heaven, pure unbridled hell, which heightens the semantic specifications of the following nominal description. On the basis of close analysis of synchronic and diachronic data, it is argued that the peculiarities of Present-day emphasizer pure are the result of two distinct but mutually reinforcing paths of development. Emphasizing pure first appeared as a subjective heightener of emotion nouns in the syntactic environment pure + noun, in which it subsequently spread to other collocational sets. The contextual emphasizing use, e.g. in pure spirit, seems to have been a facilitating factor in this process. In the pattern pure and adjective + noun, the emphasizing use cropped up only at the end of Late Modern English as the result of leftward movement and subjectification (Adamson 2000), enabled by contextual modulation of pure by the other adjective. These two paths were linked by shared collocational sets such as the emotion nouns.
\end{abstract}

Keywords: English NP; subjectification; emphasizer; collocation; contextual modulation

\section{Introduction}

Adjectives used as "emphasizers" in the English NP such as a complete idiot, absolute rubbish, utter despair, and pure bliss convey strong speaker feeling about the entities referred to (Quirk et al. 1972: 260; Sinclair et al. 1990: 69). They express subjective meanings (as defined by Traugott and Dasher 2002), which convey the speaker's attitude towards the referent. As noted by Sinclair et al. (1990: 69), emphasizing adjectives are often used with nouns that as such evaluate the represented entity as well as with nouns describing emotions and inherently scalar notions. In other words, they have a heightening effect on both the descriptive and the evaluative semantic features inherent in the nominal descriptions with which they are used. 
Regarding terminology, we will systematically use "emphasizer / emphasizing" for the heightening of a noun or a complex nominal description by an adjective - the phenomenon that we are concerned with in this article - as in pure delight, pure elemental energy. For the distinct phenomenon of submodification of adjectives, typically by adverbs, as in fairly pretty, the terms "intensifier / intensifying" will be used.

Emphasizers may be collocationally restricted to specific sets of head nouns (Sinclair et al. 1990: 69) such as raving which is typically used with the set madman / lunatic / loon / nut, etc. as well as with some other collocates such as success and fan. Emphasizers also often orient towards either predominantly positive or negative collocates. For instance, utter predicts mostly negative nominal descriptions such as utter disgust / nonsense / rubbish / madness (see also Bublitz 1996). Perfect, by contrast, tends to strengthen the positive semantic specifications of nouns such as perfect gentleman / harmony / sense.

By contrast, pure occurs with a great variety of nouns in Present-day English, which may have either a positive or a negative aura, e.g. pure joy / pleasure / luck / heaven versus pure brutality / filth / hogwash. Moreover, a striking property of emphasizer pure is that in a number of cases it is used with complex nominal descriptions consisting of adjective + noun, such as pure paranoid fantasy, pure unbridled hell. These features raise a number of questions about the development of the emphasizer use of pure. In the first place, is pure a special case of the subjectification path identified by Adamson (2000)? She has observed that adjectives may develop intensifying uses by a process of subjectification from their original descriptive senses and at the same time move to a more leftward position in the English NP. Adamson illustrated this with lovely, which originally had descriptive senses such as 'loving. It first subjectified into more evaluative senses such as 'beautiful', which in turn led to intensifying uses as in lovely long legs, in which lovely submodifies long. For the syntactic environment in which pure co-occurs with another adjective, the question can thus be asked if the development described by Adamson (2000) for lovely first applied, i.e. reanalysis from descriptive attribute to intensifying submodifier, to be followed then by further reanalysis from submodifier of the other adjective to emphasizer of the whole nominal description to its left. And how did the shift from descriptive attribute to emphasizer come about in the pattern pure + noun? Was there a relation between this shift and the developments in the multi-adjectival pattern? A second question is how pure came to be so delexicalized. Again, the question is whether mechanisms within the multi-adjectival pattern interacted with developments within the pattern pure + noun to this effect.

In this article we will address these questions by investigating synchronic as well as diachronic data from subsequent periods. On the basis of close semantic analysis of these data and quantification of the findings, we will argue that the 
emphasizer use was promoted by different mechanisms in the patterns pure and coordinated adjective + noun, and pure + noun, but that developments within these patterns also interlocked. In other words, the present characteristics of emphasizer pure are the result of two distinct but mutually reinforcing paths of development.

The structure of this article will be as follows. In Section 2 we will outline the peculiarities of emphasizer pure in Present-day English, characterizing and quantifying the different uses of pure coordinated with another adjective + noun in Section 2.1, and those of pure + noun in Section 2.2. As the specific questions about the development of emphasizer pure flow from its occurrence in these two environments, this two-legged approach will also be applied to the historical data. In Section 3.1, we will investigate the diachronic data of the multi-adjectival pattern, and in Section 3.2 those of the pattern pure + noun. We will see how the development of emphasizer uses was promoted in the former pattern by the contextual modulation of pure by another adjective and in the latter pattern by the contextual emphasizing use of pure. These two developments reinforced each other via specific collocational relations between the two patterns. In Section 4 we will draw conclusions about the development of emphasizer pure and relate these to more general questions of semantic generalization, reanalysis and subjectification.

\section{The emphasizer use of pure: Synchronic situation}

In this section we will investigate the main uses of prenominal pure in a synchronic dataset, compiled from the COBUILD corpus Wordbanks online (56 million words). ${ }^{1}$ The extractions on pure cooccurring with adjective + noun yielded 275 usable tokens, and the extraction on pure followed by noun 1175 tokens. In the Present-day English data pure thus occurs with another adjective in about one out of four cases. The following observations are based on the study of the whole dataset of pure in a string of coordinated adjectives + noun, and on a random sample of 300 , which contained 278 usable tokens, ${ }^{2}$ of pure + noun.

\subsection{Pure in a string of adjectives + noun}

The majority of the data in which pure occurs with another adjective have two adjectives, e.g. pure pitiless brutality. Sequences with three or more adjectives are rare, e.g. pure natural unbleached cotton. In 223 out of the 275 tokens, pure occurs in leftmost position, as in pure but cheap heroin, while in 52 it is preceded by an adjective, as in a brilliant, pure red, a nice, pure, gentlelady. In NPs in which pure cooccurs with another adjective, pure was found to have three uses, viz. descriptive modifier, submodifier and emphasizer. We will discuss these three uses in order, 
and comment on their collocational properties and quantitative instantiation in the data. (For general studies of the order and functions of prenominal adjectives, see Hetzron 1978; Dixon 1982; Vandelanotte 2002.)

\subsubsection{Descriptive modifier: Pure, soft distilled water}

In the first place, pure can be used as a descriptive modifier which describes properties of the entity depicted by the head noun. In the multi-adjectival pattern this is the predominant use, accounting for 135 tokens, or 49 per cent, of all examples. Descriptive prenominal adjectives are often subdivided into qualitative and classifying uses (Halliday 1985: 163-164). The former designate typically gradable qualities, while the latter form entrenched expressions together with the head noun, which name culturally recognized subtypes of the type of entity designated by that noun. Historically, classifying uses often derive from qualitative uses through entrenchment and semantic specialization: an adjective describing a typical property then becomes the culturally recognized name of a subtype, as in dry sherry (cf. Adamson 2000). For a number of reasons, this strict distinction is not very applicable to these data in which pure is coordinated with another adjective. This can be illustrated with reference to the main collocational sets of nouns pure patterns with as descriptive modifier.

The first collocational set denotes various substances (gases, liquids, and materials) such as air, water, wine, wool, gold, silver, chocolate, and so on. When these substances are called pure, it means that they are not polluted, not mixed with any impurities, additional liquids or gases. Mostly, pure is seen as a positive quality; anything infringing on that purity is negative and inferior. While pure seems to be attributed to a number of substances such as air or water as an instantial, gradable quality, we also find some expressions that appear to approximate classifier-noun status, e.g. pure chocolate, pure wool. That these combinations tend to correspond with qualitative versus classifying status respectively is confirmed by the submodification pure takes in each. Qualitative adjectives can be intensified by submodifiers such as very, extremely, etc., while submodifiers of classifiers indicate to what extent the subcategorization applies, e.g. largely, strictly (Sinclair et al. 1990: 95). With collocates like air and water, pure attracts intensifiers, e.g. the wonderfully clear, pure air, whereas with silk, for instance, it may be submodified as in 100 per cent pure silk knitted versions, where 100 per cent indicates that the type of material is nothing but pure silk. Yet, some of the multi-adjectival examples show that in typically classifying combinations, pure may still convey descriptive specifications that transcend mere subclassification, as in pure, itchy wool, pure, fluffy wool. Note also that in these examples pure is followed by a clearly non-classifying adjective, whereas classifiers typically form one unit with the head noun. In other words, tendencies towards entrenchment of classifier-noun units appear to be somewhat 
countered by relexicalization of pure. Hence, rather than forcing a strict qualitative-classifying distinction on these pure-data that is not wholly satisfactory, we will analyse all of these uses as descriptive modifiers.

A second set of collocates groups together abstract, sometimes sociocultural, concepts which in their prototypical form are seen as pure, whole, undivided, unmixed, or free of elements degrading their original purity: light and colours, voices and sounds, one's identity and ascendance (blood), genetic types and races, and theories or schools ("isms" such as evangelism and Marxism). Infringing on the purity of these concepts is usually conceived of as in some way negative and degrading. Again, some of these uses are clearly qualitative, e.g. pure and exhilarating voices, the pure noble flavour of the Riesling, her equally pure Caucasian handmaids, while others tend more towards delineating a subtype, e.g. pure theoretical mathematics.

A third set includes attitudes, inclinations, behaviours and emotions, e.g. wholly admirable and pure behaviour, the proud, pure tenacity of the Domina, or "Donna", the great lady of the courtly love tradition, which pure characterizes as being free of lower or debasing elements. This set is rather restricted with the descriptive modifier use of pure, but, as we will see below, contributes many collocates to its emphasizer use.

\subsubsection{Submodifier: Pure white sheets, pure industrial banks}

In its submodifying use, pure has only modifiers within its scope. For instance, in

(1) On a good night, tucked up in my high, soft bed at The Claremont, a stone's throw from Claridges, with its pure white, real linen sheets, I see myself as an avenging angel. (CB - UK books)

pure only modifies white - it does not attribute purity to the sheets. Importantly, both formal and collocational peculiarities show that this use is not equivalent to adverbial submodifiers such as very, extremely, largely, strictly. Quantitatively, it accounts for 31.5 per cent of the uses of pure in a string of adjectives.

The only gradable qualities that pure can submodify are colours: pure white, pure blue, etc. Pure can also submodify sets of subclassifications: substances and materials (cotton, wool, silk, gold, and chocolate), e.g. pure silver bracelet, and abstract domains (financial, environmental, psychological, scientific, industrial, global, political, academic), as in pure industrial banks, pure financial transactions. The first two, colours and materials, are forms which in English are typically ambiguous between adjectives and nouns (p.c. De Smet). If we look at the three collocational sets of submodifier pure in notional terms, rather than in strict word class terms, they in fact correspond to collocational sets found also with descriptive modifier

pure (see Section 2.1.1). The collocational relations that we are looking at here are simply embedded one unit more to the left and one level lower in NP structure: 
i. mod. head

a pure red

ii. subm. mod. head

pure white sheets

These collocational restrictions, which do not apply to the adverbial submodifier purely, already suggest that submodifier pure has a rather special status. Essentially, in the uses attested in the COBUILD data, pure is not perceived as having shifted to the adverb class in any clear way - not at all in the combinations with colours and materials, in which adverb purely is barely possible (? purely white trunks, ?purely silver watch), and not strongly so in the combination with abstract domains, even though these tend to alternate with the adverb, e.g. purely financial transactions. The adjective form in submodifier position in pure industrial banks is clearly less marked than that in expressions such as

(2) He's pure good actually. (Macaulay 2006: 267)

which are reported to occur in teenage Glasgow by Macaulay $(2006)^{3}$ and which do instantiate a clear category shift. (And even there, as noted by Macaulay 2006: 270 , the use of pure as an "uninflected adverb" is rather rare. $\left.{ }^{4}\right)$ Somehow, the combination of pure + adjectives designating colours, materials and domains, despite being embedded on a lower level of NP structure, seem to preserve elements both of the original form and meaning ('unmixed') of the descriptive modifier use. Note in this respect that the 'non-mixed' meaning dovetails particularly well with the function of submodifying classifiers, e.g. pure environmental effect, pure electric car, as it expresses full or strict application of the subtype. By contrast, colours seem to be the only set of gradable adjectives in which the meaning of 'non-mixedness' can be invoked to bring about a form of intensification.

In conclusion, even though pure can fulfil a submodifying function with restricted sets of adjectives, there is no evidence that it has shifted to the adverb class in these uses. Therefore, it is important to note that the issue of its development is a different one from that of adjectival forms acquiring adverbial status, such as pretty in pretty good, discussed by Nevalainen and Rissanen (2002).

\subsubsection{Emphasizing use: Pure unbridled hell}

The emphasizer use of pure represents 19.5 per cent of all the uses of pure in a string of adjectives. Both syntactically and semantically it differs from the two uses discussed so far in that it cannot be captured by a strict (sub)modification model and expresses strongly subjective rather than descriptive meaning. The boldface instances of pure in (3) and (4) are emphasizers: unlike descriptive attributes they do not allow predicative alternation ${ }^{*}$ the hard work is pure) or gradability ${ }^{*}$ very 
pure hard work) and unlike classifiers they do not form a unit with the head noun naming a subtype. Nor do they submodify only the adjective immediately following them, like the submodifying uses discussed above. Rather, pure in (3) and (4) conveys the speaker's emotions about what is named in the whole nominal string following pure.

(3) As a mother of both a 16-year-old who took GCSE this year and two older children who sat CSE and GCE examinations, I can assure the powers that be that the good results in GCSE were achieved by pure hard work. (CB UK Today)

(4) For this blonde old to the manor born, where silence is golden and you never hang out your dirty laundry to dry, the last month has been pure unbridled hell until now. Now Nancy Richardson has spoken out about the infidelities committed by her husband that has all New York talking; now she is fighting back. ( $\mathrm{CB}-\mathrm{Oz}$ News)

Grammatically, emphasizers involve a scope extension, as clearly illustrated by the multi-adjectival data. They apply to the whole syntagmatic string to their right, rather than just to the head like descriptive modifiers, or only to modifiers, like submodifiers. For instance, pure in pure hard work does not only apply to work or even to hard, but expresses the speaker's positive evaluation and heightening of the hard work in question. Similarly, pure in pure unbridled hell conveys augmented speaker feeling about the negative experiences described in (4). In this way, emphasizers transcend the strict (sub)modifying relations in the NP discussed in Sections 2.1.1 and 2.1.2. Rather, their affective meaning "overlays" the whole string that follows them (McGregor 1997: 210-211) and tends to render the modification relations between the elements within the string diffuse. The adjective following emphasizer pure may either add specifications to the head noun, as in pure racial snobbery, or may function more as a second emphasizer-like element adding force to pure, e.g. pure unbridled hell, pure unadulterated desire. The two most common emphasizer-like adjectives used with pure are simple and unadulterated.

Collocationally, the emphasizer use of pure is characterized by significant extension in comparison with the modifying uses discussed in Section 2.1.1. There is a certain continuity with the collocational set of emotions found with descriptive modifier pure, but whereas the latter attributes the quality "unabased" to them, emphasizer pure intensifies emotions. These emotions are often intense, e.g. pure Celtic fury, pure cold hatred, pure unadulterated desire, but need not be, as in pure, unadulterated friendliness.

Pure is also used to emphasize attitudes, states of mind and their products: pure, pitiless brutality, pure paranoid fantasy, pure male mythology, pure raw 
energy, pure creative impulse, pure artistic freedom, pure racial snobbery. A collocational set which is specific to emphasizer pure is that of evaluations: pure, startling nonsense, pure, unadulterated filth, pure literary artistry, pure, simple escapism. In contrast with the collocations of descriptive modifier pure, which were predominantly positive, the concepts intensified by pure also include a fair number (about 35 per cent) of negative ones.

If we want to typify the emphasizer meaning of pure, it is clear that the originally positive descriptive sense 'unmixed' has shifted to a strengthening value which applies equally to positive and negative concepts. This is a subjective meaning, and as we shall see in Section 4, the result of subjectification (Traugott 1989; Traugott and Dasher 2002). As argued by Ghesquière (2006: 23-26), it is not subjective in the weaker sense of merely describing internal experience, perception or evaluation (Traugott 1989: 34) as some descriptive uses of pure do, e.g. singularly pure and exhilarating voices, but in the strong sense of conveying the speaker's stance towards the referent (Traugott and Dasher 2002: 23; Biber 2004). De Smet and Verstraete (2006) label the first type descriptive, or ideational, subjectivity and the second enacted, or interpersonal, subjectivity. Whereas pure in for instance pure voices delineates criteria to which entities in our experience either do or do not correspond (De Smet and Verstraete 2006: 373-378), pure in pure unadulterated filth conveys the speaker's position. De Smet and Verstraete suggest that the distinction between description and expression of speaker stance tends to be formally reflected. ${ }^{5}$ As we saw, the emphasizer use of pure transcends the logical assembly of descriptive submodifying relations in the NP; it overlays - potentially extended - syntagms with affective meaning.

The characterization just given corresponds, we believe, to the general delineation and understanding of emphasizing adjectives in the literature (e.g. Quirk et al. 1972: 260; Sinclair et al. 1990: 69). We think it is necessary to add a specific subtype of emphasizing uses to this general picture, viz. contextual emphasizers. Not only pure, but also very and mere for instance (Breban and Davidse 2007), have uses which do not heighten the descriptive and evaluative specifications of the nominal description they are used with, but which convey a contextual form of emphasis. That is, the emphasizing adjective may express such relations as contrast (9), specification (7-8), augmenting (5) and diminishing (6) with other (implied) elements in the discourse. A degree of speaker judgement is involved, but it pertains primarily to the discoursal relation in question. Examples (5)-(9) illustrate how contextually emphasizing adjectives foreground the nominal referents as partaking in relations in the discourse, but do not strengthen the semantic specifications of the NPs as such. 
(5) Many commentators feel that the deadly cocktail of drugs, guns and Aids currently sweeping inner city America is threatening the very existence of Afro-Americans. (CB - UK magazines)

(6) When I walk down Nicolson Street, I close my eyes and recall the excitement I would feel at the mere anticipation of a visit to the old Empire Theatre. (CB - UK ephemera)

(7) She supposed it was just pure good fortune that you ever loved the person who was right for you. (CB - US books)

(8) Considering that 80 per cent of the price of a litre of petrol goes to the Government in tax anyway, the difference of $7 \mathrm{p}$ a litre is a lot. It's virtually pure extra profit as manufacturing, distribution and tax costs will be almost the same. (CB - UK Sunnow)

(9) ... there is none of that scapegoat social message and so on in the first episode, was there? It was pure early sexual encounters ... (CB - UK books)

For instance, very in (5) does not heighten any semantic features of the noun existence, but it augments the way in which drugs, guns and Aids threaten "even" the existence of Afro-Americans in inner city America. Similarly, mere in (6) does not diminish the anticipation as such: it stresses that "only" the anticipation of a visit already creates excitement. When pure is used as contextual emphasizer in Present-day English, it mostly conveys a specificational relation, which implies a contrast with other possible options. Pure in (7)-(9) means 'nothing but, just' and has a "selective" function similar to focusing adverbs (Sinclair et al. 1990: 427). The key point seems to be that pure specifies the most appropriate selection from a set of contrasting options, which may be explicitly mentioned in the context, e.g. manufacturing, distribution and tax costs in (8) and scapegoat social message in (9). Not uncommonly, focusing adverbs such as just and expressions like nothing but are found in the same context. In terms of formal properties, it resembles the emphasizing rather than the descriptive modifying use: it has the whole nominal description to its right in its scope, e.g. good fortune in (7), and it does not alternate with predicative position ( ${ }^{\star}$ the fortune is pure). However, as a contextual emphasizer does not heighten features of the nominal description it is used with, it may semantically have a certain affinity with the descriptive use. For instance in (7), good fortune unmixed with other factors is denoted.

\subsubsection{Conclusion}

In the multi-adjectival data, pure's main use is that of descriptive modifier (49 per cent), followed by the submodifying use (31.5 per cent). The emphasizing uses 
account only for 19.5 per cent, of which contextual emphasizing uses take up only a fraction of 1 per cent. These different uses form juxtaposed synchronic layers (Hopper 1991), which can be presumed to have resulted from diachronic change. On the basis of these synchronic data, our hypothesis was that the emphasizing use developed via scope extension from the submodifying use. It would then constitute a further step in the leftward movement and subjectification from objective attribute to intensifying submodifier described by Adamson (2000) for lovely. The emphasizing use in pure unbridled hell can be seen as taking this development one step further by heightening the whole nominal description to its right. However, to verify this hypothesis, diachronic data have to be studied (Section 3). First we will investigate the synchronic characteristics of emphasizer pure followed by noun (Section 2.2).

\subsection{Pure + noun}

In this section we will look at the emphasizing use of pure immediately preceding a noun, and how this use relates to the other prenominal uses of pure. The data for synchronic pure + noun were drawn from the COBUILD corpus using a query that extracted all occurrences of pure followed by a noun (singular or plural). This extraction yielded 1,227 hits. As it is not possible to enter a query specifying that pure may not be preceded by adjectives, the subset of tokens with adjective + pure + noun discussed in the previous section have to be subtracted from these. A random sample of 300 tokens was drawn from the original extraction, which turned out to contain 278 usable tokens. It is this set which forms the basis of the present discussion.

In this sample pure also fulfilled descriptive modifier, submodifier and emphasizing functions, but in different quantitative proportions than in the multiadjectival data. The submodifying uses ( 22 tokens, 8 per cent) were restricted to examples with nominal classifiers, e.g. pure bond markets, pure ice cream, pure maize cornflour. In a sense, these can be subtracted from the relevant data, as they are instances of the pattern pure + noun $_{1}+$ noun $_{2}$. Descriptive modifying uses (122 tokens, 44 per cent) and emphasizing uses (134 tokens, 48 per cent) were attested in almost equal proportions. Of the 134 emphasizing uses, 19 tokens were contextual emphasizers. As the emphasizing uses take up a larger proportion in the pure + noun pattern than in the multi-adjectival pattern, it should be instructive to compare the collocational sets of descriptive modifiers versus emphasizers across these two syntactic contexts.

The nouns collocating with descriptive modifier pure fall into the same basic sets as in the multi-adjectival NPs. They comprise substances, e.g. pure water / heroin / alcohol / oil, sense perceptions and abstract notions, e.g. pure voices/ 
heart/mind/soul, origin, race and land, e.g. an ethnically pure state, theories and doctrines, e.g. pure Buddhism / scholarship / mathematician, and emotions and inclinations, e.g. pure love / motives.

At first sight, we also find roughly the same sets of nouns collocating with the emphasizer use, viz. emotions: pure surprise / relief / delight / exultation / joy/anxiety; inclinations: pure forgiveness / contempt / hypocrisy / aggression / insanity; experiences: pure indulgence / hedonism / fun / pleasure; evaluations: pure excellence / class / filth / pornography / minimalism / cliché / formula / formality. As in the multi-adjectival data, many more nouns denoting emotions, inclinations and experiences co-occur with the emphasizing than with the descriptive modifier uses. And again, these collocational sets bring out the distinctness of the emphasizer use clearly. For instance, pure hypocrisy, in (10) does not describe unmixedness of that attitude, but lends force to the speaker's utterance by expressing strong feelings about what is said.

(10) Th - they print - a lot of er - a lot of crap You know we're living in a world of pure hypocrisy. That's what we're doing just pure hypocrisy. But yeah - but I - how many reports did you see about the police work? (CB - UK spoken)

However, because emphasizer uses are more common in the pure + noun pattern, all the collocational sets are more developed than in the multi-adjectival pattern. For instance, within the general set of evaluations, we find the particularly wellarticulated subset of negative evaluations stressing that something is completely untrue: pure bullshit / twaddle / rubbish / conjecture / fiction / whimsy / invention / fantasy / cinema / tosh. Of all these collocates, 53 per cent are positive and 47 per cent negative. Pure heightening just a noun thus seems even more delexicalized than pure emphasizing complex nominal descriptions.

The contextual emphasizing uses tend to be associated with notions of chance but not exclusively so, as illustrated by the following example:

(11) In the past the distinct representations of on the one hand brain function as pure anatomy and physiology, and on the other the emotional experience and behaviour of the mind, have obscured the fact that a successful model of how we function mentally needs to incorporate both these aspects. (CB UK books)

Do the quantified synchronic layers of these three uses of pure + noun suggest anything about the development of the emphasizer? The greater proportion of emphasizing uses and their more developed collocational sets may reflect that the shift towards emphasizer use started earlier in this environment. It also suggests that there must have been mechanisms promoting emphasizer use specific to this 
environment. But in order to find out which precise developments took place in the pure + noun pattern and in the pure and adjective + noun pattern - developments which led to the peculiarities of the Present-day emphasizer use of pure successive stages of historical data have to be studied. We turn to this diachronic investigation presently.

\section{Diachronic study: The development of emphasizing pure along two pathways}

In this section we will try and reconstruct the development of emphasizer pure as the result of subjectification, delexicalization and reanalysis. According to Traugott, items undergo such processes typically "in highly constrained pragmatic and morphosyntactic contexts" (Traugott 1995: 15) (see also Bybee 2003: 602). We will show how the emphasizer uses of pure developed along the two pathways associated with the two possible syntactic environments of prenominal pure:

i. $\quad \operatorname{adj}^{\mathrm{n}}$ (one of which pure) + noun (115 tokens) (Section 3.1)

ii. pure + noun (270 tokens) (Section 3.2)

Because of their syntactic, semantic and pragmatic particularities, each environment promoted emphasizer uses with different mechanisms. At the same time, these distinctly emerging developments also reinforced each other. This diachronic study is based on exhaustive data extractions of pure in these environments from the Helsinki Corpus, ${ }^{6}$ divided into the periods 1150-1500 (HELS-1, 608,570 words) and 1500-1710 (HELs-2, 551,000 words), and from the Corpus of Late Modern English ${ }^{7}$ (De Smet 2005), in which three periods are distinguished: 1710-1780 (CLMET-1, 2,096,405 words), 1780-1850 (CLMET-2, 3,739,657 words), 1850-1920 (CLMET-3, 3,982,264 words).

\subsection{Pathway 1: Pure in a string of coordinated adjectives}

Of the pattern in which pure is accompanied by one or - very rarely - more coordinated adjectives, the corpora contained 115 tokens, distributed in the following way over the five subcorpora:

HELS-1: 1150-1500: 1

HELS-2: 1500-1710: 7

CLMET-1: 1710-1780: 15

CLMET-2: 1780-1850: 51

CLMET-3: 1850-1920: 41 
As we will see, we can observe the emergence of the emphasizer use in this structural pattern as the result of reanalysis of pure + co-ordinated adjective as either submodifier of the accompanying adjective or as modifier of the adjective + noun unit. Schematically, this reanalysis can be represented as:

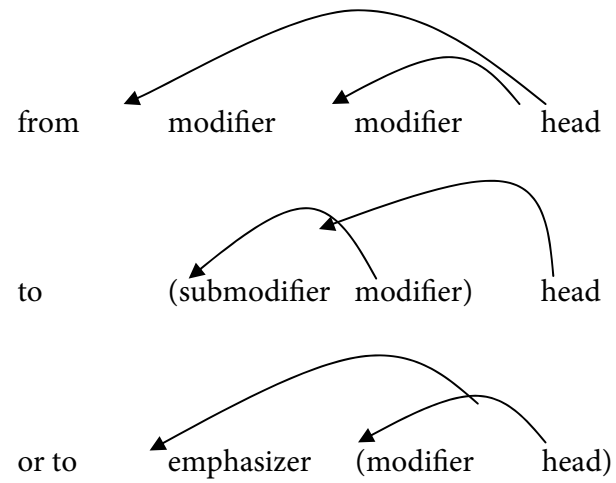

Figure 1. Reanalysis of modifier to submodifier or emphasizer

Firstly, we can witness the development of a number of formal features that facilitated this reanalysis, which are summarized in Table 1.

Table 1. Structural factors facilitating reanalysis of pure in a string of adjectives

\begin{tabular}{lcc}
\hline & leftmost & \multicolumn{1}{c}{ syndetic } \\
\hline HELS-1 (1) & $0(0 \%)$ & $1(100 \%)$ \\
HELS-2 (7) & $5(71.4 \%)$ & $5(71.4 \%)$ \\
CLMET-1 (15) & $13(86.7 \%)$ & $10(66.7 \%)$ \\
CLMET-2 (51) & $49(96.1 \%)$ & $20(51.3 \%)$ \\
CLMET-3 (41) & $35(85.4 \%)$ & $12(29.3 \%)$ \\
\hline
\end{tabular}

For one thing, pure came to favour a position to the left of the accompanying adjective(s). From the beginning of Late Modern English on, pure occurs in leftmost position in the overwhelming majority of cases: 86.7 per cent in CLMET-1, 96.1 per cent in CLMET- 2 and 85.4 per cent in CLMET-3. At the same time, there was a growing tendency for conjunctions and/or linking the attributes to be dropped. While in CLMET-1 66.7 per cent of the instances are still subsumed under the syndetic pattern pure and/or + adjective + noun, this number has dropped to 29.3 per cent in CLMET-3. The modest numbers for the oldest corpora require us to be cautious, but the overall tendencies seem clear.

Semantically, an important factor is the relative semantic indeterminacy of pure, which it manifests from the early stages on. Pure indicates a broad quality that can be applied to many entities, ranging from concrete nouns such as air and water to abstract ones such as hearts, souls, styles and ecstasy. In the data we can 
observe how the coordinated adjectives (fresh, transparent, humble, generous, true, spiritual, rectified, etc.) are usually lexically more specific, containing more semantic features. For instance,

(12) $[\ldots] \&$ on the toppe of it a Well of pure fresh water. (HELs-2, J.Taylor, All the workes of John Taylor, the Water Poet. 1630)

(13) Elizabeth wanted to keep the English Church a pure and true branch of the Church, free of the mistakes that had crept in before her father's time. (CLMET-3, C. Yonge, Young Folk's History of England. 1873)

(14) If they [“jottings for articles and essays, disjointed and disconnected", SV \& $\mathrm{KD}$ ] are interesting when enlarged to the size of an article, what must they be in their concentrated form? Pure rectified spirit, above proof; before it is lowered to be fit for human consumption: "words that burn" indeed. (cLmet-3, T. Hardy, A Pair of Blue Eyes. 1873)

The main semantic factor enabling the structural reanalysis of pure as submodifier or emphasizer is, we will argue, its contextual modulation (Croft and Cruse 2004) by the adjectives coordinated with it. The original basic senses of pure were 'unmixed, unalloyed, unadulterated' in a physical sense (as of the thirteenth century, e.g. air, water, gold, etc.), or in a non-physical 'morally untainted' sense (as of the fourteenth century, e.g. heart, soul, friendship, morality, widowhood, etc.) (Murray et al. 1933: 1614). A consequence of pure's general semantics is that its meaning tends to be contextually modulated by the accompanying adjective. Croft and Cruse (2004) characterise contextual modulation as an extremely weak form of polysemy: the various 'senses' of a word do not stem from (semi)autonomous semantic units within the word, but "[t]he specifying features of different contextual modulations are, as it were, contributed by the context, not selected, or their creation triggered, by context" (Croft and Cruse 2004: 140).

The combination of pure and an adjective with more lexical content brings semantic components to the fore that would otherwise be unprofiled or non-existent. In each of these examples, the quality pure seems to be contextually linked to the other quality mentioned. In (12) the water is called pure precisely because it springs forth from a well. The element of freshness is not intrinsically part of pure, but is a contextual effect. Similarly, the purity of the English church in (13) is linked to its being true to the original understanding of it. In the metaphorical example (14) the contextual modulation foregrounding the semantic feature 'high-level alcohol' is contributed partly by the head noun spirit, as well as by rectified (rectifying is the term for refining or purifying alcoholic beverages through distillation). Spirit, rectified and pure all express (or at least imply) the particularly high degree of alcohol, and this semantic cohesion makes it unclear what pure 
exactly modifies: does it attribute a quality to the head noun, or was it added to lend (ironic) emotional strength to the speaker's characterization of the disconnected jottings in question?

This analysis of contextual modulation also extends to other occurrences of pure: in pure and innocent mind (CLMET-1), for instance, pure and innocent boil down to the same idea, viz. 'morally untainted'. Other examples include pure and humble religion (CLMET-1), in which humility is associated with genuine religiosity, and pure, unearthly ecstasy (CLMET-3), where pure means something like 'otherworldly'. Analogous examples are: pure and chaste esposage (HELS-2), pure bashful maiden (CLMET-2), pure and undefiled religion (CLMET-2), pure, spiritual paleness (CLMET-2), pure ethereal essence of existence (CLMET-2), etc.

In this way, through contextual modulation pure acquires new senses and extends its range of collocating head nouns. However, because of the semantic redundancy between the coordinated adjectives, this also leads, as pointed out by Sinclair $(1992)^{8}$ to inevitable delexicalization of pure. In this way, pure thus gradually becomes semantically even more general in the double sense of applying to more contexts (Traugott 1989: 48) and of being bleached semantically (Harris and Campbell 1995: 92). This is conducive to leftmost pure acquiring emphasizing force in two ways.

Firstly, the repetition of two near-synonymous adjectives such as pure and simple, pure and true is as such a weak form of emphasis (Martin forthcoming). If we take together the contextual modulation and the formal tendencies represented in Table 1, we see that pure came to frequently introduce an asyndetic pair of prenominal adjectives that make up a contextual semantic unit. It is easily conceivable that pure in cases such as pure ethereal essence of existence (CLMET-2), pure, benevolent love (CLMET-3) and pure unmixed fear (CLMET-2) will lose in attributehood; it will be felt to enhance the sense of its accompanying adjective rather than independently attribute a quality. ${ }^{9}$ The emphasizer use of pure followed by a second emphasizer-like adjective, such as simple or unadulterated, in Present-day English emerged from these partly pleonastic expressions such as pure and unmitigated romance (CLMET-3).

Secondly, the delexicalization which affected pure as a result of contextual modulation also facilitated the development towards emphasizer use. This delexicalization enabled the re-analysis of pure as submodifier or as emphasizer. This gradual emergence of these 'strengthening' uses can be traced in the successive diachronic datasets. Whereas HELS-1, HELS- 2 and CLMET-1 contain only descriptive modifier uses of prenominal pure, scattered instances of submodifying uses first crop up in CLMET-2 and continue in CLMET-3. In four examples in CLMET-2 pure can be interpreted as a submodifier of a colour adjective. Two of those, (15) and (16), remain vague as to the precise status of pure; these are so-called bridging 
contexts (Evans and Wilkins 2000), which allow for both readings, descriptive attribute and intensifying submodifier, and thus facilitate reanalysis.

(15) ... vast level space; now hailing one group of beloved friends, and now another. Mortals newly ushered by death into this world of pure blue sky and boundless meads, see the long-lost objects of their affection ... (CLMET-2, W. Beckford, Dreams, Waking Thoughts, and Incidents. 1783)

(16) flowery surface, and shortly perceived among the grass an oblong basin, incrusted with pure white marble. Most of the slabs are large and perfect, apparently brought from Greece, and still retaining ... (CLMET-2, W. Beckford, id. 1783)

(17) was beautiful - a splendid place carpeted with crimson, and crimsoncovered chairs and tables, and a pure white ceiling bordered by gold, a shower of glass-drops hanging in silver chains from the ... (CLMET-2, E. Brönte, Wuthering Heights. 1847)

In (15) and (16) the colour name forms quite a strong collocation with its head noun: blue sky, white marble. Perhaps this is the source of the submodifier reading of pure - the combination of adjective and noun is so entrenched that they form a kind of semantic unit, and it remains vague which element pure is ascribed to. ${ }^{10}$ No such collocational relation exists between white and ceiling in (17), whose most convincing reading is the one in which the white is pure, rather than the ceiling. Examples like (17) are the earliest instances in our data in which pure unambiguously submodifies a colour.

CLMET-2 also contained a number of examples in which pure submodifies a classifying adjective, e.g.

(18) ... general the parsimonious Spaniard; - another argument in favour of their pure Gothic descent; for the Maragatos, like true men of the north, delight in swilling liquors and battening upon gross and ... (CLMET-2, G. Borrow, The Bible in Spain. 1842)

(19) ... short time we were surrounded by a large group of the nearly pure Indian inhabitants. They were much surprised at our arrival, and said one to the other, "This is the reason we ... (CLMET-2, C. Darwin, The Voyage of the Beagle. 1839)

Pure in (18) is a bridging context: pure may be read as ascribing a quality to descent, but it also allows a reading in which pure modifies the classifying adjective only (the descent is pure Gothic). In (19), by contrast, nearly pure unambiguously modifies classifier Indian: it is the Indian genetic origin that is judged to be nearly pure, not the inhabitants. In (19), the submodifier pure is itself submodified by 
nearly, which further contributes to indicating how strictly the category Indian applies. CLMET- 3 contains similar cases of pure used as submodifier of colour adjectives and classifying adjectives.

It is in CLMET-3 that attributes with emphasizer features and a few instances of emphasizer use crop up. An example of each is given here:

(20) I closed my eyes; I put his hand, in a kind of spiritual self-forgetfulness, to my lips. He murmured a soft remonstrance. Oh the ecstasy, the pure, unearthly ecstasy of that moment! I sat - I hardly know on what - quite lost [...]. (CLmet-3, W. Collins, The Woman in White. 1859-60)

(21) ... the summer boarders, and one of the town officials patrolled and perspired till he shone all over with pure civic pride. (CLMET-3, R. Kipling, Captains Courageous. 1897)

Example (20) is one of two instances where pure, while possibly complying with some formal tests of a qualitative attribute (? the very pure ecstasy) also displays characteristics of emphasizer use. Predicative alternation does not work well for this example (?the unearthly ecstasy was pure), in which the repetition of ecstasy and the exclamatory mood foreground an emphasizing reading of pure. In (21) intensification of pure by very is excluded ( very pure civic pride) and the humorous tone also contributes to pure expressing speaker stance rather than describing a quality. Table 2 represents the emergence of submodifiers and emphasizers in these multi-adjectival data in quantitative terms.

Table 2. Submodifying and emphasizing uses in data with pure in a string of adjectives

\begin{tabular}{lcc}
\hline & submod. & emphas. \\
\hline HELS-1 (1) & $0(0.0 \%)$ & $0(0.0 \%)$ \\
HELS-2 (7) & $0(0.0 \%)$ & $0(0.0 \%)$ \\
CLMET-1 (15) & $0(0.0 \%)$ & $0(0.0 \%)$ \\
CLMET-2 (51) & $12(23.5 \%)$ & $0(0.0 \%)$ \\
CLMET-3 (41) & $10(24.4 \%)$ & $4(9.8 \%)$ \\
\hline
\end{tabular}

Throughout this section we have argued that the shift from descriptive modifier to submodifier and emphasizer in these data is semantically driven by contextual modulation. This contextual modulation is part of a larger process of collocational extension of the head nouns co-occurring with pure, which we will reconstruct in the final part of this section. Because of the limited number of tokens in the earliest datasets not too much can be staked on the relative proportions found in these.

More or less from its origins pure co-occurs with concrete head nouns such as air and water, and abstract nouns such as faith, Latin, esposage and forme. As shown by the figures in Table 3, the collocational set of abstract concepts, often 
religiously inspired, numerically predominated from an early stage on (HELS-2). In CLMET-2, head nouns of two new semantic fields are added: colours and emotions. The former facilitates the development of submodifying uses, while the latter is important in the emergence of emphasizer uses. In CLMET-2, the collocational set of abstract concepts undergoes diversification and is the scene of noticeable contextual modulation, which enriches pure with (weak) new senses such as 'doctrinally original' (pure and genuine doctrines) and 'otherwordly' (pure spiritual paleness). It is these that in a later stage lead to emphasizer-like uses such as pure, unearthly ecstasy (CLMET-3) and pure Darwinian imperatives (CB). In CLMET-3, finally, it is mainly the concrete entities collocating with pure that diversify further: along with the well-established air we also find mud and streams, and entities such as voice are also attributed the quality 'pure.' Table 3 gives an overview of the collocational sets found with pure in the successive diachronic datasets.

In short, this increase and diversification of collocates can be taken to underlie the ongoing changes discussed in the first part of this section: prenominal pure, as it more and more frequently precedes a descriptive modifier, is applied to more contexts over the course of two centuries. The contextual-semantic process that appears to instigate the change from descriptive modifier to emphasizer is contextual modulation, which is present not only in the emergent emphasizer uses such as pure civic pride (21), but also in the earliest instances of intensifying submodifiers such as pure blue sky (15) and pure white marble (16). Pure in a string of adjectives thus constitutes one pathway to emphasizer use. In this syntactic environment, it is leftward movement and subjectification as envisaged by Adamson (2000) that lead firstly to submodifying and secondly to emphasizing uses. Importantly, the diachronic data in which pure cooccurs with other prenominal adjectives manifest only facilitating factors and the initial stages of the emphasizing use of pure.

\subsection{Pathway 2: Pure followed by noun}

The data on pure in a string of coordinated adjectives were studied separately because it was hypothesized that the factor 'leftness' played a major role. This section will be concerned with the complementary set of data, where pure directly precedes its head noun without any other adjectival elements. These data were extracted from the Helsinki corpus and the CLMET corpus in the same way as the other diachronic data: by entering the query pure and manually deleting all irrelevant instances. In all, 270 examples remained, distributed over the five subcorpora as follows:

HELS-1: 1150-1500: 12

HELS- 2: 1500-1710: 14 


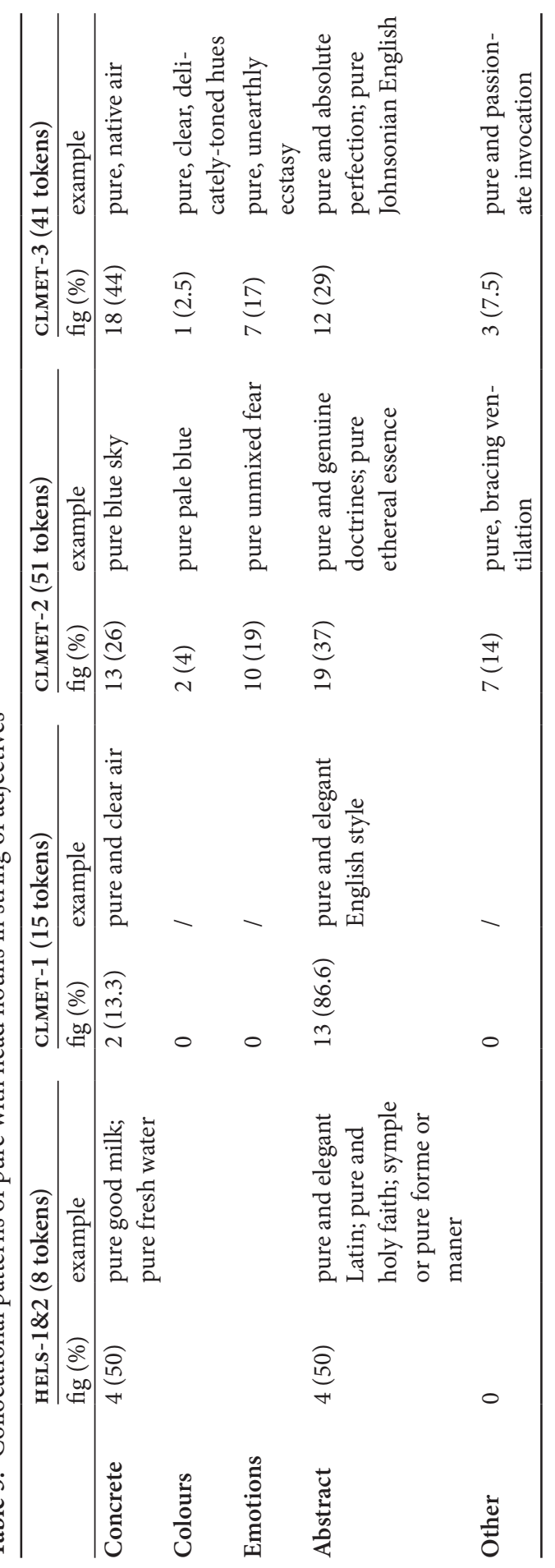


CLMET-1: 1710-1780: 48

CLMET-2: 1780-1850: 83

CLMET-3: 1850-1920: 123

These figures already suggest that pure extends to more and more contexts, an important proportion of which will prove to be emphasizer use.

The particular syntactic structure of the datasets allows us to make some predictions as to the results they will yield. In the present dataset, the development of submodifiers will be a marginal phenomenon; the focus taken will thus strongly lie on the development of the emphasizer use. The specific format of the pure + noun data implies that the factors involved in the rise of the emphasizer use (be they syntactic, semantic or pragmatic) will differ from those involved in the syntactic context of asyndetically coordinated adjectives with a strong tendency to contextual modulation. The combination of those factors opened up a specific possibility of reanalysis, which is structural in nature and not likely to be repeated in other syntactic contexts, whereas the reanalysis to be discussed in this section will be semantic in nature. The main factor in these data is a context of emotional involvement. Essentially, the nouns which pure came to modify increasingly denoted an emotion that could be emphasized. This shift can best be described by discussing the collocational patterns first.

Table 4 gives an overview of the types of collocates pure + noun is associated with in the successive diachronic stages. Most of the semantic classes run parallel to those discerned for diachronic pure in a string of adjectives (Table 3), but in contrast with Table 3, the collocational set of concrete entities decreases over time, while that of abstract ones increases. Most importantly, pure is more strongly associated with emotions throughout the entire corpus. The set of emotions and mental states is larger and more differentiated than in the previous dataset and expands through time. It really takes off in CLMET-1, where it accounts for a third of the data, rises to roughly half in CLMET- 2 and then drops off again to a third in CLMET-3. This is the class that drives the shift from descriptive pure + noun to emphasizing adjective. It is present in Table 3 , though only marginally as a separate set, and its rise there coincides with that of the emphasizer use.

Table 5 sets out the figures charting the development of descriptive, contextual emphasizing and ordinary emphasizing uses in the pure + noun data. Qualitative and quantitative study of these data suggests that in the gradually increasing shift from descriptive modifier to emphasizer, the contextual emphasizing use, which has properties of both, may have played an important role. We will discuss these three uses, and the way they developed in the historical data.

In a first step, up to CLMET-2, the great majority of attestations are descriptive modifiers. In CLMET-3, the descriptive modifier uses drop off and stabilize 


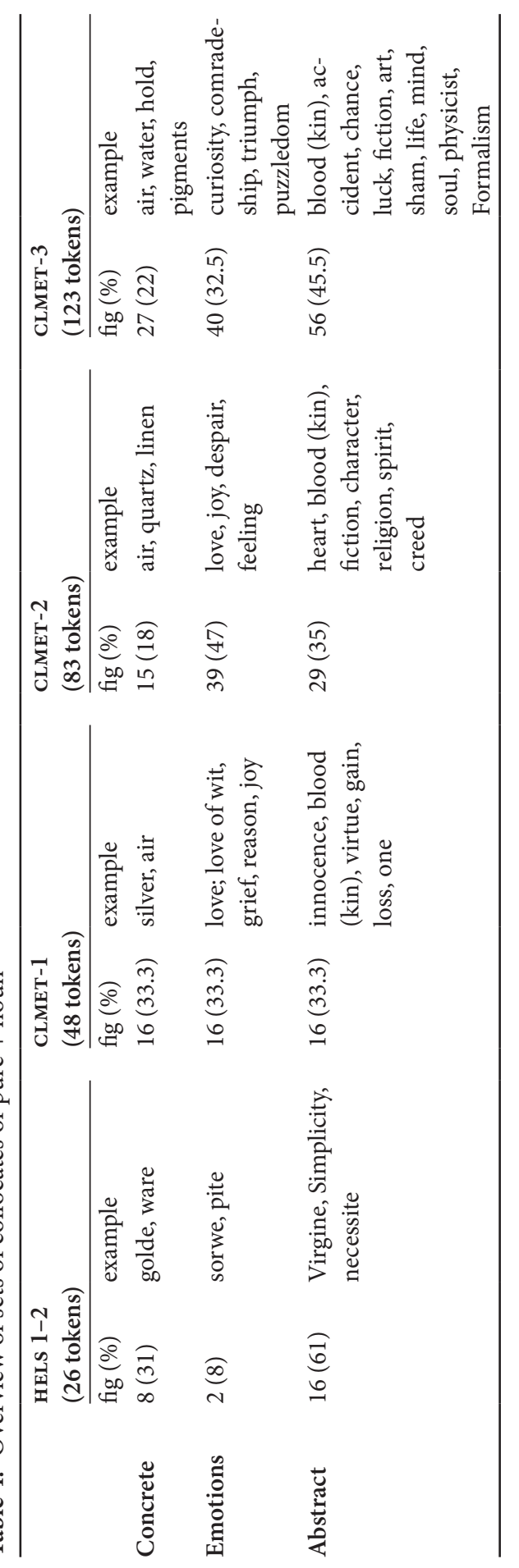


Table 5. Distribution of descriptive, contextual emphasizing and emphasizing uses of pure in pure + noun data

\begin{tabular}{lccc}
\hline & desc.modifier & cont. emphas. & emphasizer \\
\hline HELS-1 (12) & $8(66.6 \%)$ & $2(16.6 \%)$ & $2(16.6 \%)$ \\
HELS-2 (14) & $12(85.7 \%)$ & $2(14.3 \%)$ & $0(0.0 \%)$ \\
CLMET-1 (48) & $32(66.6 \%)$ & $12(25.0 \%)$ & $4(8.4 \%)$ \\
CLMET-2 (83) & $59(71.1 \%)$ & $8(9.6 \%)$ & $16(19.3 \%)$ \\
CLMET-3 (123) & $58(47.2 \%)$ & $26(21.1 \%)$ & $39(31.7 \%)$ \\
\hline
\end{tabular}

at just under 50 per cent, more or less the proportion they are still at in Presentday English. The head nouns being descriptively modified are all those listed under the heading 'concrete' in Table 4, but also emotions and abstract notions such as love $(23,24)$, innocence, desire, blood (25), morals and constitutions, spirit, and sentiments.

(23) The difficulty then is, why any objects ever cause pure love or hatred, and produce not always the mixt passions of respect and contempt. (CLMET-1, D. Hume, A Treatise of Human Nature. 1739-40)

(24) ... pride in ourselves: For which reason the view of them, as belonging to another person, produces pure love, with but a small mixture of humility and respect. It is easy to extend the same reasoning to the opposite ... (CLMET-1, D. Hume, id. 1739-40)

(25) That thou mayest be by kings, or wh ${ }^{\star * *}$ s of kings.

Boast the pure blood of an illustrious race, In quiet flow from Lucrece to Lucrece (CLMET-1, A. Pope, An Essay on Man. 1733-34)

In these examples, pure denotes primarily the quality of unmixedness of the substances, emotions or abstract concepts talked about. In CLMET-3 and the Presentday English data, the descriptive modifier use manifests two changes. Firstly, its association with emotions diminishes; we have seen how in Present-day English only a limited set of emotions and attitudes are qualified as pure. Secondly, more classifying uses come into existence through the entrenched combination of pure with nouns such as wool.

In the early stages, the second most common use is the contextual emphasizing use: HELS-1: 16.6 per cent, HELS-2: 14.3 per cent, CLMET-1: 25 per cent, illustrated by (26)-(29):

(26) For it is best whan it is in pure spirit, withoutyn specyal thought or any pronounsyng of worde (HELs-1, The Cloud of Unknowing, 1350-1420) 
(27)

... makers are forced to multiply: - Forced, I say, as things stand; human laws not being a matter of original choice, but of pure necessity, brought in to fence against the mischievous effects of those consciences which are no law... (CLmet-1, L. Sterne, The Life and Opinions of Tristram Shandy. 1759-67)

(28) ... when it applies sometimes to the pure intellect, sometimes to the affections; ... (CLMET-1, D. Hume, Dialogues Concerning Natural Religion. 1779)

(29) This cannot take place with regard to pride and humility; because these are only pure sensations, without any direction or tendency to action. (CLMET-1, D. Hume, A Treatise of Human Nature. 1739-40)

In these examples pure appears to have lost its status as descriptive attribute. If we apply the predicative alternation test, the results are either awkward or ungrammatical ( ${ }^{*}$ the necessity is pure) or do not correspond to the meaning conveyed in the original example. For instance, example (26) conveys that praying is carried out best "purely in spirit", without explicit thoughts or words. It does not stipulate that the thoughts of the prayer have to be "pure". Still, pure can be taken to indicate that necessity is unmixed with choice in (27), the intellect not mingled with affections in (28), and the sensations completely distinct from actions in (29). The contrasting elements have been italicized in these examples. As noted in Section 2.1.3, the contextual emphasizing use of pure is typically specificational. In this respect, its function is similar to that of focusing adverbs such as purely, just. The item marked as pure constitutes the most appropriate selection from a set of contrasting options, which in the diachronic data tend to be explicitly mentioned in the surrounding discourse. In the synchronic data, the contrasting values could also be implied, for instance by the use of copular or extraposition constructions as in it was just pure good fortune that you ever loved the person who was right for you. As a specificational or focusing element, pure no longer indicates a quality or distinguishes an entity from other entities by virtue of its superior quality, but discriminates it by dint of its appropriateness or need of contrastive emphasis. This is why we have characterized this use of pure as a contextual emphasizer. It does not strengthen the categorial specifications of the nouns it cooccurs with (necessity, intellect, etc.), but focuses on these entities in contrast with other values, which is a contextual form of emphasis.

Some cases offer interesting clues about the sort of context in which the shift from attribute to contextual emphasizer can take place:

(30) [T]he fear prevails still more and more, till at last it runs insensibly, as the joy continually diminishes, into pure grief. After you have brought it to this 
situation, diminish the grief, ... (CLMET-1, D. Hume, A Treatise of Human Nature. 1739-1740)

Example (30) can be given either interpretation: pure may refer either to the unmixed quality of the emotion or it may indicate that the non-mixing of categorial specifications ('just grief') is appropriate in this context. This is a bridging context which supports both the readings of 'unmixed grief' and 'nothing else but grief', and illustrates how the shift from 'unmixedness' to 'descriptive appropriateness' may come about. ${ }^{11}$ It is telling that this vague example deals with emotions, for it is precisely in this semantic field that the further changes are initiated.

Up to CLMET-2, contextual emphasizing uses occur, besides in the expression "of pure necessity", almost exclusively with nouns describing an emotion or a related notion such as state of mind or experience. The correlation then drops to eleven out of 26 in CLMET-3. Proportionally, the contextual emphasizing uses of prenominal pure seems to have peaked at about 20 to 25 per cent in Late Modern English (Table 5 above). In the synchronic data, it has tapered off to only 7 per cent.

The third prenominal use of pure, the emphasizing use proper, is also present from the earliest stages on. After taking a slower start than the contextual emphasizing use, its numerical importance systematically increases in CLMET-2 (19.3 per cent) and CLMET-3 (31.7 per cent) to occupy a proportion of 41 per cent in Present-day English.

The earliest examples of this emphasizer use arise in contexts which are not only descriptions of emotions but also contexts of strong emotional involvement: the emotions described are intense or even paradoxical, emotion is heightened in the whole surrounding context ( $\mathrm{cf}$ so afraied, the height of his spirit, thin herte stirid, etc. in 31), and subjective empathy is thus created. All these properties are illustrated by the first two emphasizer uses, which both involve the prepositional expression "for pure ..." in our data. One cannot help but notice the affinity with a typical early constructional environment of the contextual emphasizing use, viz. of pure necessite.

(31) He that is thi deedly enmye, and thou here him so afraied that he crye in the height of his spirit this lityl worde fir, or this worde oute: yit, withoutyn any beholdyng to hym for he is thin enmye, bot for pure pité in thin herte stirid and reisid with the doelfulnes of this crie, thou risist up, ... (HELs-1, The Cloud of Unknowing 1350-1420)

(32) Wherof his herte is so distraght, That he for pure sorwe hath caght The maladie of which nature Is queint in very creature. (HELs-2, J. Gower, Confessio Amantis, or, Tales of the Seven Deadly Sins. 1376-79?) 
These examples differ in two important ways from the contextual emphasizing uses. First, there is no overt mention of any contrasting emotions: the feelings of pity and sorrow are communicated to the hearer as the only ones relevant at that point in the discourse. Second, and as a result of this, the intensity of the emotions itself is emphasized, not any contrast with other emotions. In these contexts, the notion of "unmixedness" expressed by pure has shifted to that of intensity. This shift is a case of subjectification in the sense that the expression of speaker stance becomes the main component of the new meaning (Traugott and Dasher 2002: 23).

In CLMET-1, emphasizing uses of pure with emotion nouns still occur in prepositional phrases such as "out of pure ..." and "through pure ...", but have extended to attitudes and milder emotions, which, as we have noted in the Present-day English data (Section 2.1.3), can also be heightened, e.g.

(33) Her head's untouched, that noble seat of thought: Such this day's doctrine - in another fit she sins with poets through pure love of wit. (CLMET-1, A. Pope, An Essay on Man. 1733-34)

In this period, pure is also used as emphasizer of nouns such as gentleman - often in ironic contexts:

(34) ... cursing and reviling him; in which latter the landlord joined, saying, "Ay, ay, he is a pure one, I warrant you. A pretty gentleman, indeed, to go for a soldier! He shall wear a laced wastecoat truly. [...]" (CLMET-1, S. Fielding, The Governess; or, The Little Female Academy. 1749)

In CLMET-2 $(34,35)$ (16 per cent) and CLMET-3 (36) (32 per cent), emphasizers have come fully into their own, expressing strong speaker stance. No less than twelve out of 16 instances of pure modify emotion nouns in CLMET-2 (75.0 per cent), though their share drops to 19 out of 39 in CLMET-3 (48.7 per cent).

(35) Not so Mr. Edgar. He grew pale with pure annoyance - a feeling that reached its climax when his lady rose, and stepping across the rug, seized Heathcliff's hands again, and laughed like one beside herself. (CLMET-2, E. Brönte, Wuthering Heights. 1847)

(36) "There, that is pure awkwardness! Why did you hold the candle horizontally? Be quick, and bring another." (CLMET-2, E. Brönte, id. 1847)

(37) Well, this poor angel, having made up her mind to take compassion upon my son, when he had saved her life so many times, persuades him to marry her out of pure pity, and throw his poor mother overboard. (CLMET-3, R. Blackmore, Lorna Doone, A Romance of Exmoor. 1869) 
In CLMET-2, the emphasizer use is no longer restricted to the constructional context of prepositional phrases, as illustrated by (36), where it occurs in an exclamative, a construction with intrinsically heightened emotional force.

In CLMET-3, it detaches itself from its collocational preference for emotion nouns, and also emphasizes abstract notions and evaluations, as in the pure impossibility, pure chivalry, pure sham, pure stupidity, pure seamanship. By that time, pure has become a general purpose emphasizer and is well under way to developing the semantically very general emphasizing value it has in Present-day English.

In this section it has become clear that the general collocation of pure with emotion nouns (which is much more prominent here than in the multi-adjectival data) has played a central role in the development of the emphasizer use. Up till CLMET-1, pure is frequently used as descriptive modifier of emotion nouns. The descriptive use of pure gradually loses this collocational set, first to the emergent contextual emphasizing use, and later definitively to the emphasizer use proper. The two types of emphasizing uses are strongly associated with emotion nouns when they develop their own senses, but afterwards spread to other contexts. The most intriguing question raised - but not solved - by these data is whether the emphasizer developed from the contextual emphasizing use.

A number of arguments can be given for setting up the hypothesis that the rise of the emphasizer use followed the customary path $\mathrm{A}>\mathrm{A} / \mathrm{B}>\mathrm{B}$ proposed by Traugott and Dasher (2002). In this path, $A$ is the attribute use, B the emphasizer use and $\mathrm{A} / \mathrm{B}$ the contextual emphasizing use, which combines features of both. This hypothesis has a certain plausibility both analytically and in view of the quantitative patterns observed in the data. As noted above, the contextual emphasizing use can be seen as analytically inbetween descriptive and emphasizing use. On the one hand, it still denotes unmixedness, like the descriptive use, and on the other it involves contrastive emphasis, which relates it to the emphasizing use. Quantitatively, the contextual emphasizing use is the one that takes off first, taking some collocates from the descriptive use, after which it declines relative to the emphasizing use, which ends up taking away most of the emotion nouns set from the descriptive modifier use. This pattern is compatible with a development in which the contextual emphasizing use forms the stepping stone for the emphasizing use. By the same token, the diachronic pure + noun data do not offer compelling evidence to accept this hypothesis as fact. Most importantly, the emphasizing use of pure appears in equally early data (1250-1350) as the contextual emphasizing use. On this basis, it cannot be said for sure that the former developed from the latter. More diachronic studies of contextual emphasizing uses and emphasizing uses of, for instance, related adjectives such as mere, sheer and utter will have to be carried out before any firm conclusions can be drawn about the diachronic relation between the contextual emphasizing and the ordinary emphasizing use. At this stage, all 
that can be said is that the contextual emphasizing use, in virtue of collocational, constructional and semantic similarities, has facilitated the development of the emphasizing use of pure.

In conclusion to this section, it can be said that the pattern in which pure is followed by a head constitutes the main pathway to emphasizer use. The diachronic data display the emergence and increased productivity of the emphasizer use of pure: 8.3 per cent of the data for CLMET-1 consist of emphasizers, which rises to roughly 20 per cent for CLMET-2, to a third in CLMET-3, and to 41 per cent in Present-day English. The shift from descriptive modifier to emphasizer use turned out to be strongly associated with emotion nouns: pure shifts from describing their unmixedness to expressing the speaker's heightening of them, a clear process of subjectification. In this process, the contextual emphasizing use of pure was found to be a facilitating factor, and possibly even the intermediate step.

\section{General conclusion}

In this article we have investigated the complex developments by which adjective pure shifted from descriptive to emphasizer use. The main reason of this complexity lies in the two patterns in which pure has always occurred: either co-occurring with (an)other adjective(s) followed by a noun or followed immediately by a noun. The relative proportions themselves of these two patterns have changed over time, as shown by Table 6 . In this table it is the relative percentages rather than the actual numbers that are important. The size of the different corpora differs, but from each, exhaustive extractions of the two patterns were made, whose relative proportions vis-à-vis each other can hence be calculated.

The multi-adjectival pattern peaks in terms of relative frequency in CLMET-2, where it occurs roughly one out of 1.5 times. Then it drops off to one out of three in CLMET- 3 and one out of four in the COBUILD data. Presumably, this change is related to the semantic and functional changes pure underwent in the two patterns, the

Table 6. Relative proportions of the two syntactic environments of pure in the different corpora

\begin{tabular}{lccc}
\hline & pure and adjective + noun & pure + noun & total pure-data \\
\hline HELS-1 & $1(8 \%)$ & $12(92 \%)$ & $13(100 \%)$ \\
HELS-2 & $7(33 \%)$ & $14(66 \%)$ & $21(100 \%)$ \\
CLMET-1 & $13(21 \%)$ & $48(79 \%)$ & $61(100 \%)$ \\
CLMET-2 & $51(38 \%)$ & $83(62 \%)$ & $134(100 \%)$ \\
CLMET-3 & $41(25 \%)$ & $123(75 \%)$ & $164(100 \%)$ \\
COBUILD & $275(19 \%)$ & $1175(81 \%)$ & $1450(100 \%)$ \\
\hline
\end{tabular}


Table 7. Relative proportions of emphasizers and of uses related to emphasizing uses

\begin{tabular}{lllll}
\hline & $\begin{array}{l}\text { pure and } \\
\text { adjective + noun: } \\
\text { submodifier }\end{array}$ & $\begin{array}{l}\text { pure and } \\
\text { adjective + noun: } \\
\text { emphasizer }\end{array}$ & $\begin{array}{l}\text { pure + noun: } \\
\text { contextual } \\
\text { emphasizer }\end{array}$ & $\begin{array}{l}\text { pure + noun: } \\
\text { emphasizer }\end{array}$ \\
\hline HELS-1 & $0 \%$ & $0 \%$ & $16.6 \%$ & $16.6 \%$ \\
HELS-2 & $0 \%$ & $0 \%$ & $14 \%$ & $0 \%$ \\
CLMET-1 & $0 \%$ & $0 \%$ & $25 \%$ & $8.5 \%$ \\
CLMET-2 & $23.5 \%$ & $0 \%$ & $10 \%$ & $19 \%$ \\
CLMET-3 & $24.5 \%$ & $10 \%$ & $21 \%$ & $32 \%$ \\
COBUILD & $31.5 \%$ & $19.5 \%$ & $7 \%$ & $41 \%$ \\
\hline
\end{tabular}

most important of which is the development of emphasizer use, as summarized in Table 7. In the pure + noun pattern, emphasizer uses are present from the earliest data on and systematically increase through time, reaching 41 per cent in the COBUILD data. In the multi-adjectival pattern, the emphasizer use emerges only in CLMET-3 (1850-1920) with a proportion of 10 per cent, from which it increases to 19.5 per cent in Present-day English.

The earliest context in which the emphasizer use arose was that of pure subjectively heightening a noun expressing an emotion, in the absence of other prenominal adjectives and in the absence of a contrasting emotion. In this pattern, we also found a second extended use of pure, which seems to have at least helped along this reanalysis as emphasizer, viz. the contextual emphasizing use. It combines properties of descriptive modifier and emphasizer use, and its quantitative development relative to the emphasizer use can be seen in Table 7. It is possible that descriptive senses of pure, which ascribe a quality to the entity depicted by the noun, e.g. pure blood (25), first shifted to contextual emphasizing uses, which delineate the categorial specifications of a noun without heightening them, e.g. in pure spirit (26). These contextual emphasizing uses may then have formed the intermediate step towards emphasizing uses, which do heighten the evaluative and descriptive features of nouns, as in pure sorwe (32). Both types of emphasizing uses were first predominantly used with emotion nouns, the most prominent collocational set in the diachronic data of the pure + noun pattern, and spread afterwards to other collocational sets. After having contributed to the meaning extensions from the descriptive uses of pure, and having detached part of the collocational set of emotion nouns from these descriptive uses, the contextual emphasizing use declined relative to the emphasizing use. However, we could not definitively deduce from the pure + noun data whether the shift to contextual emphasizing use actually preceded that to emphasizing use, or whether these two extended uses developed in an intertwined way.

In CLMET-3, pure also cropped up as emphasizer followed by another adjective + noun. In the structural environment of coordinated adjectives, formal and 
semantic facilitating factors had been at work throughout the preceding stages. Pure came to occupy the leftmost position in an asyndetic string of prenominal adjectives, the combination of which tended to bring out shared semantic features (which were sometimes also contained in the meaning of the noun). This semantic cohesion loosened up the structural dependency ties within the noun phrase: it was no longer unambiguously clear what modified what. As a result, pure was reanalysed first as an intensifying submodifier and soon after as an emphasizer. The latter expression of speaker stance was taken to envelop the entire noun phrase to its right, effectively constituting an increase in scope. As shown by Table 7, both the submodifying and the emphasizing uses of pure continued to go up in the subsequent historical stage, Present-day English, with the submodifying use still quantitatively ahead of the emphasizer use.

We have thus shown that the shift to emphasizer use manifested by pure is the result of two distinct but partly related and mutually supporting pathways. They are related mainly through the collocational set of the emotion nouns, which in the early stages was more prominent in the pure + noun pattern, but spread to the emphasizing uses found in both that pattern and the multi-adjectival environment. The change in the quantitative proportions of the two patterns may also have been influenced by some of the developments described in this article. Conceivably, the semantic enrichment brought about by contextual modulation may have been a factor in the temporary high relative frequency of the multi-adjectival pattern in CLMET-2. After that, the delexicalization caused equally by contextual modulation, and the rise of submodifying and emphasizing uses of pure may have made it less fit to co-occur with coordinated adjectives.

What are the contributions of this study to the general discussion of semantic change, re-analysis and subjectification? Firstly, the two pathways to emphasizer use outlined here show an adherence to local formal and semantic properties: the phenomena involved in re-analysing and subjectifying descriptive modifiers are different according to the syntactic contexts. This confirms the claim that such semantic shifts and structural changes originate in quite specific contexts in which the actual reinterpretation occurs (Traugott 1995: 15; Bybee 2003: 602). Secondly, the collocational analysis applied consistently throughout the data has brought out and confirmed underlying tendencies that would have been difficult to assess otherwise. By combining the observation of historical changes associated with local constructions with a systematic collocational analysis, it has been possible to give a comprehensive account of the rise of emphasizing pure.

Where subjectification and re-analysis specifically in the English NP are concerned, the study of pure co-occurring with another adjective + noun has both confirmed and extended Adamson's (2000) hypothesis. It was shown that the process of leftward movement and subjectification leading to the intensifying of a 
prenominal adjective can have the heightening of adjective + noun as its next step. Contextual modulation (Croft and Cruse 2004) was singled out as the more finegrained semantic change enabling this. The semantic generalization (delexicalization) and extension of pure to more contexts turned out to be actually preceded by contextually induced semantic enrichment of this lexical item. It will be interesting to see whether this specific angle on semantic generalization proves relevant to other contexts involving the collocation of near-synonymous items. Finally, the hypothesized shift from descriptive modifier to contextual emphasizing and to emphasizing uses of adjectives - which evokes the cline propositional - textual - interpersonal (Traugott 1989) - also seems to deserve further study. It should be instructive to study other adjectives such as for instance mere and very, which, besides ordinary emphasizing uses, also have contextual emphasizing uses which augment or, in the case of mere diminish, contextual relations as in (5) and (6) quoted in Section 2.1.3. Historic case studies of these adjectives should allow to solve questions that had to be left pending in this study, viz. whether distinguishing the contextual emphasizing use from the emphasizing use has general theoretical-descriptive relevance, and whether the contextual emphasizing use is diachronically intermediate between descriptive and emphasizing senses.

\section{Notes}

* We sincerely thank a number of people for their crucial help in carrying out and writing up this study. Tine Breban kindly extracted the data from the Helsinki corpus for us and An Van linden provided the references and dates of the diachronic examples cited in this article. Hendrik De Smet and Lieven Vandelanotte read and marked the Advanced MA thesis by Sigi Vandewinkel, supervised by Kristin Davidse, which lies at the basis of this article. They contributed greatly to it by their constructive criticisms, helpful suggestions and added insights. The subsequent synchronic data description and the analysis of the Helsinki data presented in this article were carried out by Kristin Davidse and differs from Vandewinkel (2005). Special thanks are due to Elizabeth Traugott who generously commented on the issues discussed in this article and directed us to some essential studies on this topic. Finally, we are very grateful to the anonymous referee whose thoughtful comments helped us greatly with the revision of this article.

1. The COBUILD corpus Wordbanks online consists of about 56 million words. It is geographically diversified, containing mainly British English subcorpora, but also some American English datasets and one Australian English subcorpus. It is also diversified in terms of register: its British and American subcorpora include texts from radio broadcasts, novels, and 'ephemera' such as advertisements and leaflets; samples of quality versus popular newspapers and spontaneous dialogue are only provided for British English; the Australian corpus consists of newspaper language. All examples marked CB are extracted from the COBUILD corpus Wordbanks online and are reproduced here with the kind permission of HarperCollins. These examples are also followed by the name of the subcorpus from which they were extracted. 
2. To extract pure co-occurring with another adjective in both syndetic and asyndetic strings, queries were used in which one word was allowed to intervene between pure and the other prenominal adjective. This meant that some non-usable tokens such as the sequence pure, at high altitude were also extracted. The extractions on pure + noun equally included non-usable tokens, for instance compounds such as pure-breds.

3. Possibly, our COBUILD data contain one example in which pure is used as a general intensifier that does manifest category shift, viz. I'm out for breakfast at my local pub where I'm sure I spot the bloke who demonstrates the prizes on STV's Wheel of Fortune. No, it can't be. Pure dead big superstars like the Wheel of Fortune Prize Guy wouldn't do breakfast in my local (UK - Sunnow). In this (almost self-consciously) informal example pure is followed by dead, another typical intensifier of adjectives in certain regional varieties (Macaulay 2006: 270).

4. As noted by Stoffel (1901: 14), a general intensifying use of pure akin to adverbial very was more common in Middle English and Early Modern English, e.g. There is good lond, but it is pure litille (Sir John Maundeville [ed. Halliwell], p. 130).

5. Ghesquière (2006: 23-26) discusses the formal reflexes of the interpersonally subjective status of emphasizing adjectives such as pure in detail.

6. The diachronic part of the Helsinki Corpus of English Texts contains samples of continuous text covering the period from c. 750 to 1700, i.e. Old English, Middle English and early Modern (British) English. Texts were selected in such a way as to reflect socio-historical variation. Periodization was of primary importance, but attention was also paid to geographical dialect, type and register of writing (text type, relationship to spoken language, setting on formal-informal axis) and sociolinguistic variation (different author-related parameters such as gender, age, social rank). Pure was found only from Middle English on, and the examples cited are hence followed by the abbreviations HELS-1 for Middle English and HELS-2, for Early Modern English. For each example cited in this study the date and the reference are indicated.

7. The Corpus of Late Modern English (CLMET) covers the period 1710-1930, subdivided into periods of 70 years each, i.e. 1710-1780 (CLMET-1), 1780-1850 (CLMET-2), and 1850-1920 (CLMET-3). It has been compiled on the basis of texts from the Project Gutenberg and the Oxford Text Archive. It consists of text samples from a great variety of authors, mostly male but including some women authors, from different social backgrounds. Varied text types have been included with a preference for non-literary texts over literary ones, and texts from lower registers over higher registers, whenever a choice could be made among the texts produced by a particular author. For all examples the date and the reference are indicated.

8. Sinclair (1992: 17) argues that in partly redundant expressions such as physical assault and scientific experiment, the adjective is delexicalized.

9. It is important to note that pure followed by a noun describing an emotion did not have an emphasizing value from the start. This is shown by the occurrence of pure in predicative position, which is incompatible with emphasizing value in early examples such as If then there be any Addition of Good to any Man's Misery, is not he happier than another, whose Misery is pure and simple, without the mixture of any manner of Good. (HELs-2, P. Richard, Anicius Manlius Severinus Boetius, Of the consolation of philosophy. 1695) 
10. This analysis of collocationally motivated vagueness is supported by the fact that in CLMET-2 we find both a pure evening blue and a pure unclouded morning sky (S. Coleridge, Biographia Literaria. 1817.)

11. We thank Lieven Vandelanotte for discussion of this example in its extended context.

\section{References}

Adamson, Sylvia. 2000. A lovely little example. Word order options and category shift in the premodifying string. In: Olga Fischer, Anette Rosenbach and Dieter Stein (eds.). Pathways of Change. Grammaticalisation in English. Amsterdam: John Benjamins, 39-66.

Biber, Douglas. 2004. Historical patterns for the grammatical marking of stance: A cross-register comparison. Journal of Historical Pragmatics 5.1, 107-136.

Breban, Tine, and Kristin Davidse. 2007. Subjectification and structural movement of prenominal adjectives in the English NP: A diachronic perspective. Paper presented at Colloque Adjectifs, Lille, 13-15 September 2007.

Bublitz, Wolfram. 1996. Semantic prosody and cohesive company: 'somewhat predictable'. Leuven Contributions to Literature and Philology 85.1, 1-32.

Bybee, Joan. 2003. Mechanisms of change in grammaticization: The role of frequency. In: Brian Joseph and Richard Janda (eds.). The Handbook of Historical Linguistics. London: Blackwell, 602-623.

Croft, William, and Alan Cruse. 2004. Cognitive Linguistics. Cambridge: Cambridge University Press.

De Smet, Hendrik. 2005. A corpus of Late Modern English. ICAME-Journal 29, 69-82.

De Smet, Hendrik, and Jean-Christophe Verstraete. 2006. Coming to terms with subjectivity. Cognitive Linguistics 17, 365-392.

Dixon, Robert. 1982. Where have all the adjectives gone? And other Essays in Semantics and Syntax. Berlin: Mouton.

Evans, Nicholas, and David Wilkins. 2000. In the mind's ear: The semantic extensions of perception verbs in Australian languages. Language 76, 546-592.

Ghesquière, Lobke. 2006. 'The complete fool and the little old lady'. A Synchronic and Diachronic Study of the Prenominal Adjectives old, little, complete. MA Thesis. Linguistics Department. University of Leuven.

Halliday, Michael. 1985. An Introduction to Functional Grammar. London: Arnold.

Harris, Alice, and Lyle Campbell. 1995. Historical Syntax in Cross-linguistic Perspective. Cambridge: Cambridge University Press.

Hetzron, Robert. 1978. On the relative order of adjectives. In: Hansjakob Seiler (ed.). Language Universals. Tübingen: Gunter Narr Verlag, 165-184.

Hopper, Paul. 1991. On some principles of grammaticization. In: Elizabeth Traugott and Bernd Heine (eds.). Approaches to Grammaticalization. Volume I: Focus on Theoretical and Methodological Issues. Amsterdam/Philadelphia: John Benjamins, 17-35.

Macaulay, Ronald. 2006. Pure grammaticalization: The development of a teenage intensifier. Language Variation and Change 18, 267-283.

Martin, James. Forthcoming. What kind of structure? Interpersonal meaning and prosodic realization across strata. WORD. 
McGregor, William. 1997. Semiotic Grammar. Oxford: Clarendon Press.

Murray, James, Henry Brodly, William Craigie and Charles Onions (eds.). 1933. The Oxford English Dictionary. Oxford: Oxford University Press.

Nevelainen, Terttu, and Matti Rissanen. 2002. Fairly pretty or pretty fair? On the development and grammaticalization of English downtoners. Language Sciences 24, 359-380.

Quirk, Randoph, Sidney Greenbaum, Geoffrey Leech and Jan Svartvik. 1972. A Grammar of Contemporary English. London: Longman.

Sinclair, John. 1992. Trust the text. In: Martin Davies and Louise Ravelli (eds.). Advances in Systemic Linguistics. Recent Theory and Practise. London: Pinter, 5-19.

Sinclair, John et al. 1990. Collins COBUILD English Grammar. Birmingham: HarperCollins.

Stoffel, Cornelis. 1901. Intensives and Down-toners. A Study in English Adverbs. Heidelberg: C. Winter's Universitätsbuchhandlung.

Traugott, Elizabeth. 1989. On the rise of epistemic meanings in English: An example of subjectification in semantic change. Language 65, 31-55.

Traugott, Elizabeth. 1995. The role of the development of discourse markers in a theory of grammaticalisation. Paper presented at ICHL. Available at: http://www.stanford.edu/ traugott/ ect-papersonline.html

Traugott, Elizabeth, and Richard Dasher. 2002. Regularity in Semantic Change. Cambridge: Cambridge University Press.

Vandelanotte, Lieven. 2002. Prenominal adjectives in English: Structures and ordering. Folia Linguistica 36.3, 219-259.

Vandewinkel, Sigi. 2005. Attitudinal Adjectives and Category Shift in the Nominal Group. MA Thesis. Linguistics Department. University of Leuven.

\section{Authors' addresses}

Sigi Vandewinkel / Kristin Davidse

K.U. Leuven

Linguistics Department

Blijde-Inkomststraat 21

3000 Leuven

Belgium

kristin.davidse@arts.kuleuven.be

\section{About the authors}

Sigi Vandewinkel was awarded an Advanced MA in Linguistics by The University of Leuven in 2005 on the basis of his thesis on Attitudinal Adjectives and Category Shift in the Nominal Group.

Kristin Davidse is Professor of English Linguistics at The University of Leuven (K.U.Leuven). Her main research interest is the description of English grammar from a functional-cognitive perspective, on which she has published articles in journals such as Linguistics, Cognitive Linguistics, Folia Linguistica and WORD. Her current interest is grammaticalization and emergent grammar in the English NP; she is supervising a number of research projects on this topic at K.U. Leuven. 